\title{
HYBRID INTERCONNECTION OF I.C.'S BY MEANS OF PATTERNS ON FLEXIBLE TAPE
}

\author{
A. VAN DER DRIFT and K. F. NICKL VAN NIKELSBERG \\ The Netherlands, N. V. Philips' Gloeilampenfabrieken, Eindhoven, Holland
}

(Received March 20, 1977)

\begin{abstract}
Mounting of I.C.'s on thickfilm circuits by means of patterns on foil of a total thickness of about 30 microns is described. The extreme flexibility of the foil and some well controlled characteristics of the thickfilm process aid soldering of the chip with a reproducible low heat resistance to the substrate in a cheap and reliable way.
\end{abstract}

\section{INTRODUCTION}

Integrated circuits are of increasing importance in electronics. Nevertheless, the need for second level integration remains. In searching for the lowest-cost solution it is not sufficient simply to develop an inexpensive I.C.; the whole function has to be taken into account. In the mass production of Philips television sets this has led to a hybrid unit in which the I.C. is mounted on a thickfilm circuit by means of a pattern on a flexible tape (Figure 1). Many I.C.manufacturers apply patterns on tape for mounting

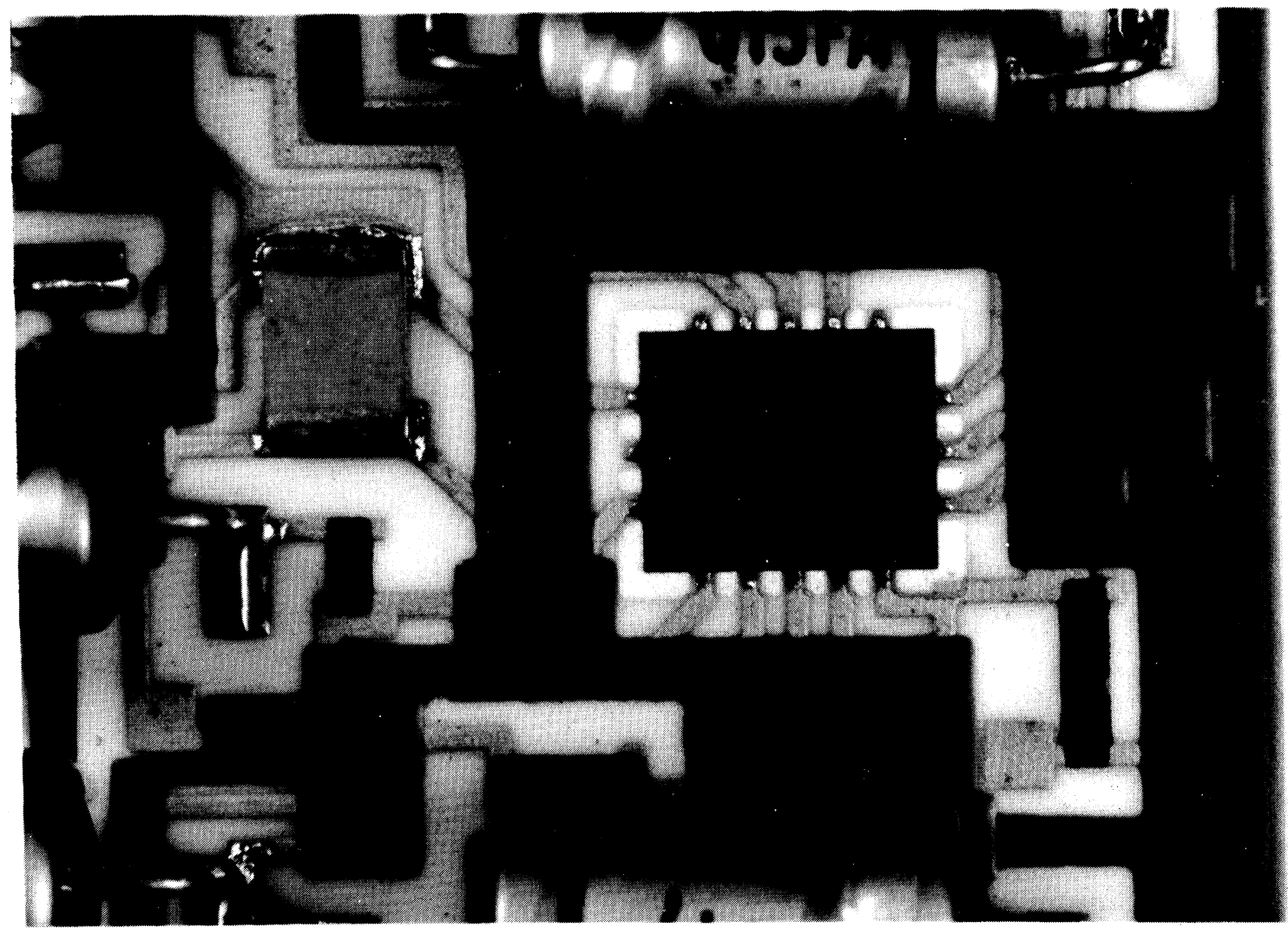

FIGURE 1 Photograph of a part of a thickfilm unit with an I.C.-on-tape mounted onto it. 
TABLE I

Foil-mounting compared with face-down mounting

\begin{tabular}{|c|c|}
\hline Advantages & Disadvantages \\
\hline Dimensions comparable with other components. & Requires more substrate area. \\
\hline Lower heat resistance to substrate. & Longer electrical leads. \\
\hline Direct electrical contact with the rear of the crystal. & Twice the number of joints per lead. \\
\hline \multicolumn{2}{|l|}{ Functional testing before mounting easily possible. } \\
\hline $\begin{array}{l}\text { No stresses on the bumps, hence no thermal fatigue, } \\
\text { as would be the case in the rigid face down } \\
\text { configuration. }\end{array}$ & \\
\hline
\end{tabular}

I.C.'s inside the dual-in-line (DIL), ${ }^{1}$ few of them for mounting I.C.'s in hybrids. ${ }^{2}$

We will make clear why we mount I.C.'s using special flexible patterns, how we do that and in what respects it differs from other approaches.

\section{UNDERLYING PRINCIPLES}

The most important function of the pattern on tape is to extend the bonding pads of the IC-chip, which are small, to dimensions comparable with other components. Once this is done I.C.'s are no longer special components in this respect as they would be in case of face down mounting. Face down mounting is the most direct and compact connection of I.C.'s, hence often recommended. Let us see whether this is always true. Table I shows the most important advantages and disadvantages of mounting by means of patterns on tape as compared to face down mount- ing. It depends on the application which method is preferred.

The advantages mentioned in Table I are only true provided the tape fulfils certain requirements. For testing on the reel and for functioning in application the leads must be isolated from each other. High reliability at high levels of dissipation require the pattern-on-tape to be as flexible as possible. At the same time this flexibility makes the required substrate area smaller. In our application mounting by means of our own-made flexible tape appears to be the best choice. We use a special, very low-cost process for applying metal patterns 5 to 10 microns thick to 25 micron thick kapton foil. ${ }^{3}$ Flexibility of the individual leads, which in the method adopted by most I.C.-manufacturers ${ }^{1}$ is achieved by removing the somewhat stiff kapton locally is unecessary in our case. Our alignment is not achieved by means of holes in the tape; optical alignment patterns are employed when great precision is demanded (Figure 2).

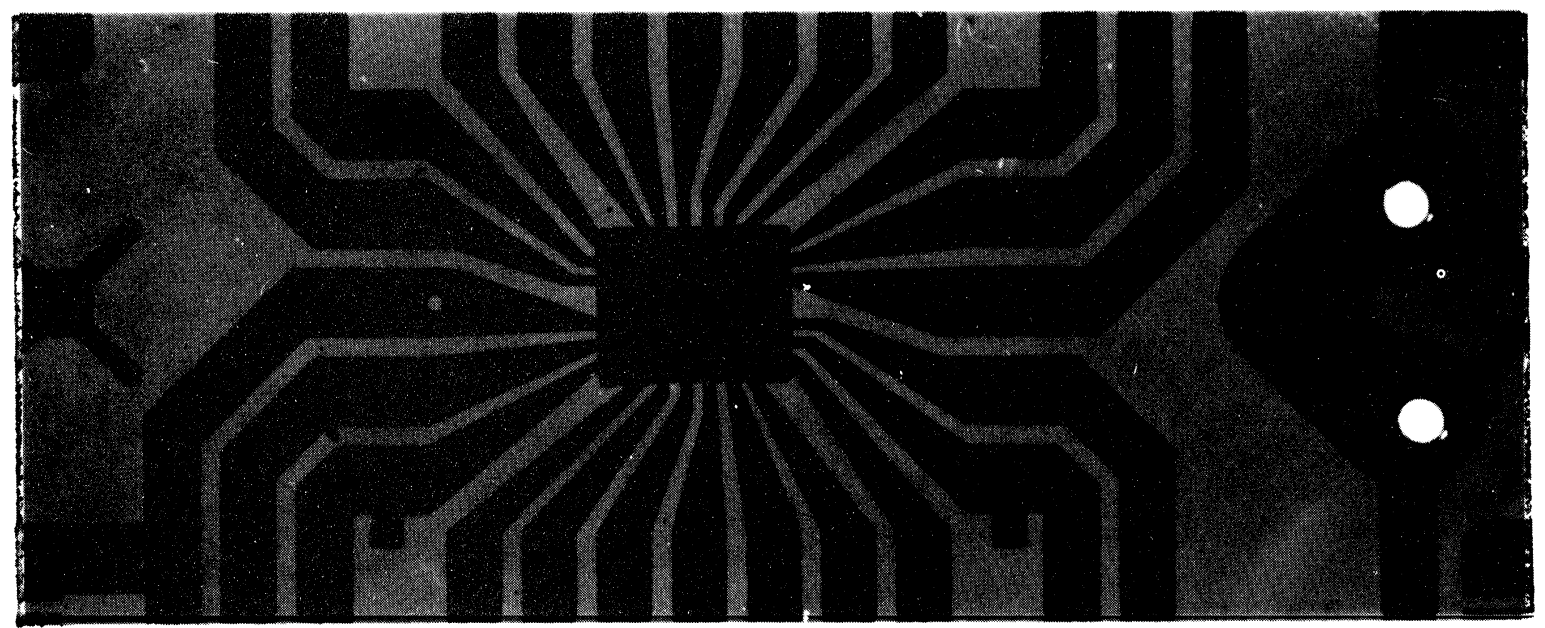

FIGURE 2 Photograph of an interconnection pattern on tape onto which a chip is mounted. Patterns for alignment (left side) and for test results (right side) have been applied. 


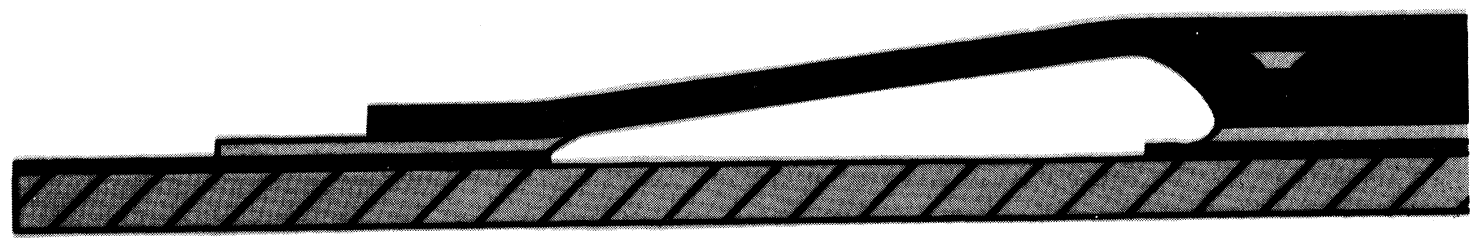

FIGURE 3 Schematic drawing of IC-on-tape mounted onto thickfilm. The chip (right side) is connected in two ways to the substrate, the outerlead bonding (left side) and the chip-backbonding (right side).

\section{MOUNTING PROCEDURE}

The innerlead bonding, described elsewhere ${ }^{3}$ leads to an intermediate product: I.C.'s on the reel (Figure 2). How is this intermediate product connected to thickfilm? Figure 3 roughly shows the geometry. Two kinds of connections, both by means of solder, can be distinguished, the backbonding and the outerlead- bonding. This paper is chiefly concerned with the former.

The backbonding must be carried out in such a way that the heat resistance from chip to substrate is low and has a reproducible value. Moreover, no solder may be forced out, which could cause shorts. In conclusion this means the solder should exactly cover the back-area of the crystal and have a defined

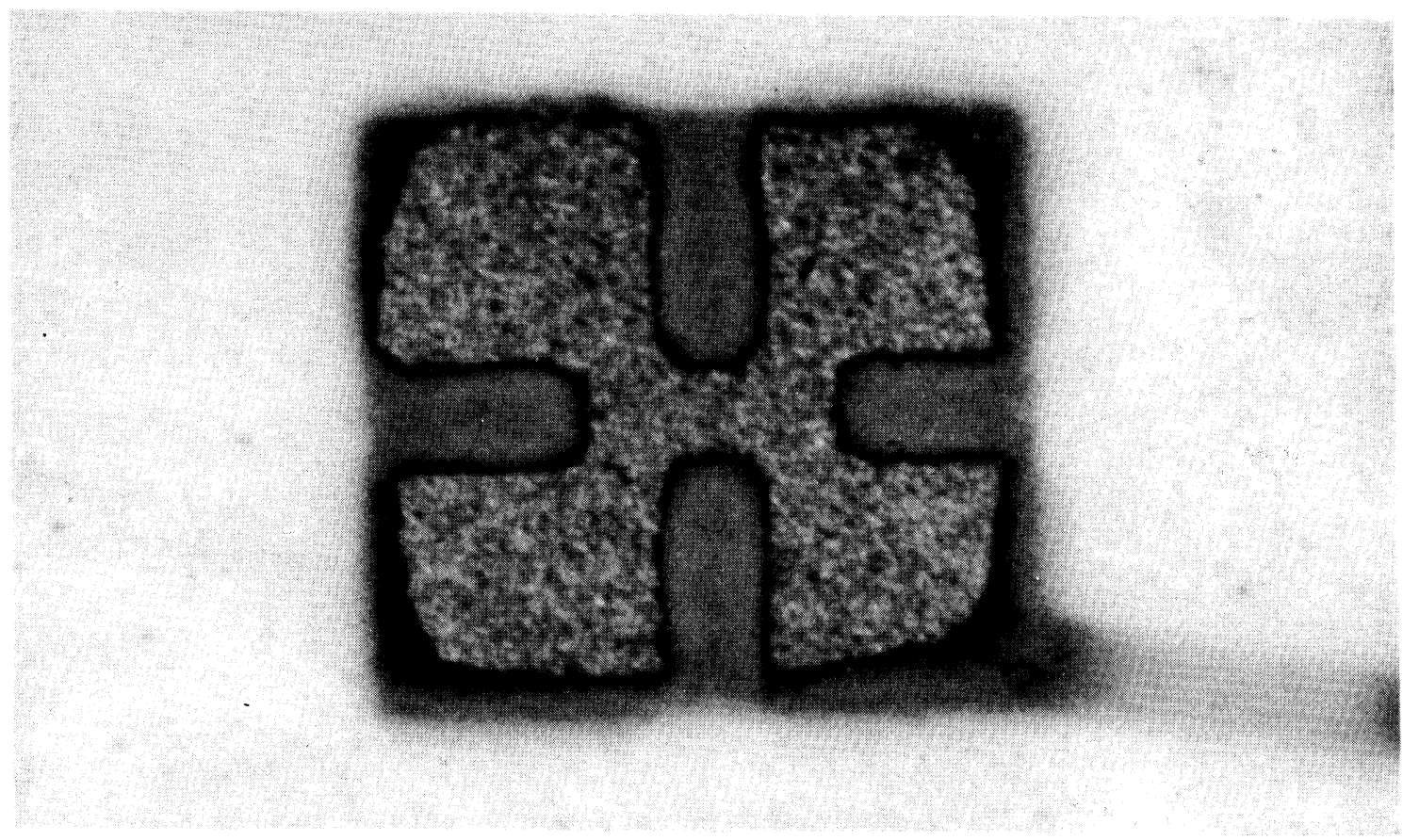

FIGURE 4 Photograph of the thickfilm at the site where the chip has to be mounted. The square conductor, connected to earth potential (vague corridor) is surrounded and partly covered by the dielectric layer. 
thickness. The solution had to be built-in to the whole of the process and be self-adjusting. Fortunately use could be made of some characteristics of the thickfilm process.

In the thickfilm process patterns of different materials are screenprinted with narrow tolerances in line widths and thicknesses in order to keep the value of the integrated thickfilm components within the required tolerances. The distance between the I.C.chip and the substrate is determined by making use of the thickness of a dielectric layer employed for making cross-overs, whereas the volume of the applied solder is determined by pattern and thickness of the solderpaste that is also screenprinted. The volume of the solder and the distance between chip and substrate determine the area covered by solder. Figure 4 shows a possible layout of the dielectric layer in which you see the "fingers" supporting the chip.

The connection between outerleads and thickfilm conductors is made in a way similar to that just described.

\section{RESULTS}

The distance between chip and substrate, about 20 microns, can be determined to within a few microns. With a chip of $3 \mathrm{~mm}^{2}$ mounted on a 2 in. by 1 in. substrate a thermal conductivity of $52 \pm 1^{\circ} \mathrm{C} / \mathrm{W}$ has been achieved. It remains nearly constant in life tests.

In the products, made at our laboratory we did not find any failure due to thermal fatigue of the bumps, being the most fragile connection. We carried out $10^{8}$ thermal cycles (between $25^{\circ} \mathrm{C}$ and $125^{\circ} \mathrm{C}$; cycle time $3 \mathrm{~min}$.) on the bumps. This is in accordance with the expectations, because the flexible pattern does not exert any substantial force on the bumps.

\section{CONCLUSION}

By making use of some characteristics of the thickfilm process and of a very flexible pattern on thin kapton foil, mounting of I.C.-chips onto thickfilm circuits is possible in a reproducible, cheap and reliable way as required in quantity production of hybrid circuits at Philips.

\section{REFERENCES}

1. J. Lyman, Special report: film carriers star in high-volume I.C. production, Electronics, 48, 25 Dec. 1975, p. 61 .

2. G. Dehaine and K. Kurzweil, Tape automated bonded moving into production, Solid State Technol., 18, October 1975, p. 46.

3. A. van der Drift, W. G. Gelling and A. Rademakers, Integrated circuits with leads on flexible tape, Philips' Tech. Rev., 34, 1974, p. 85. 

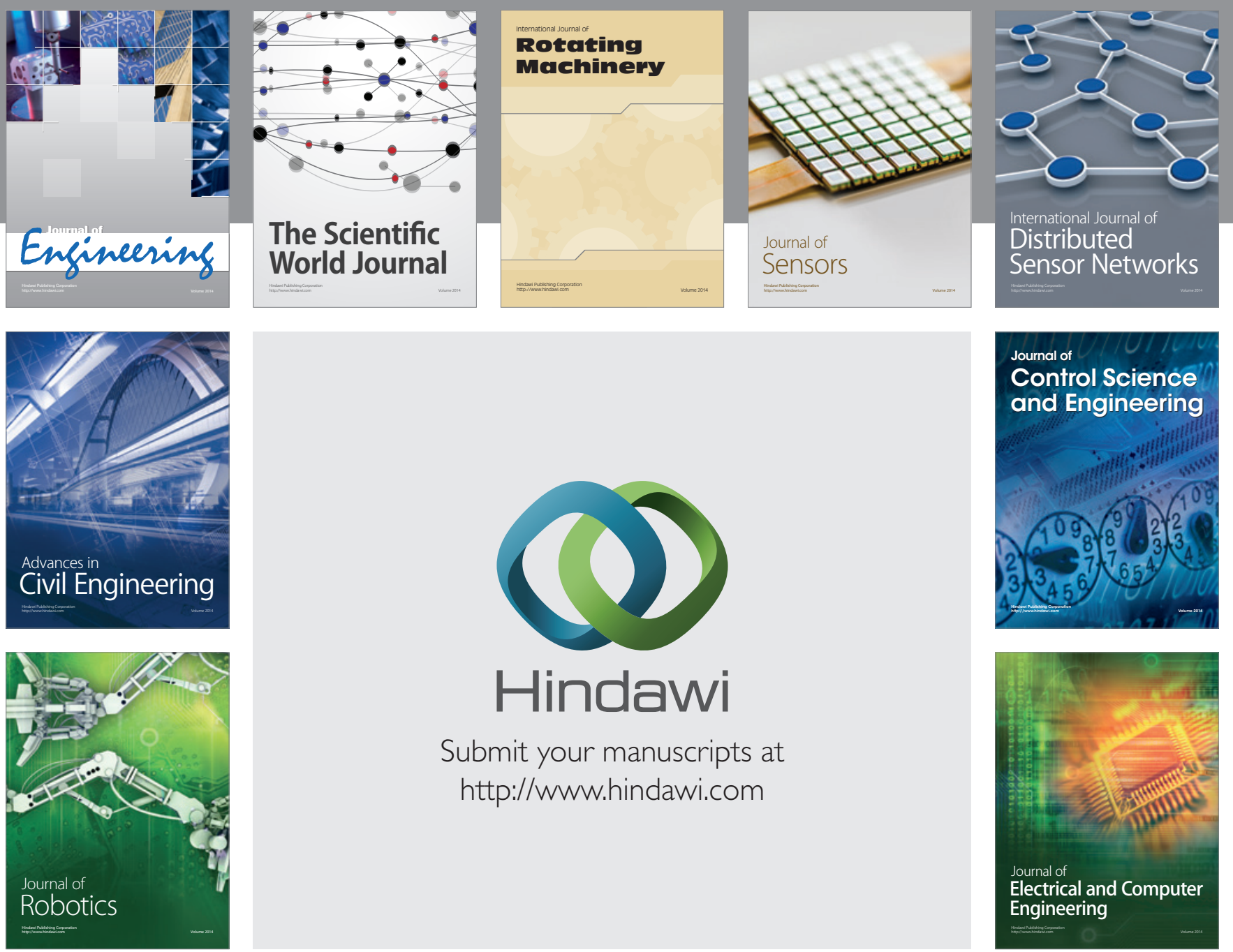

Submit your manuscripts at

http://www.hindawi.com
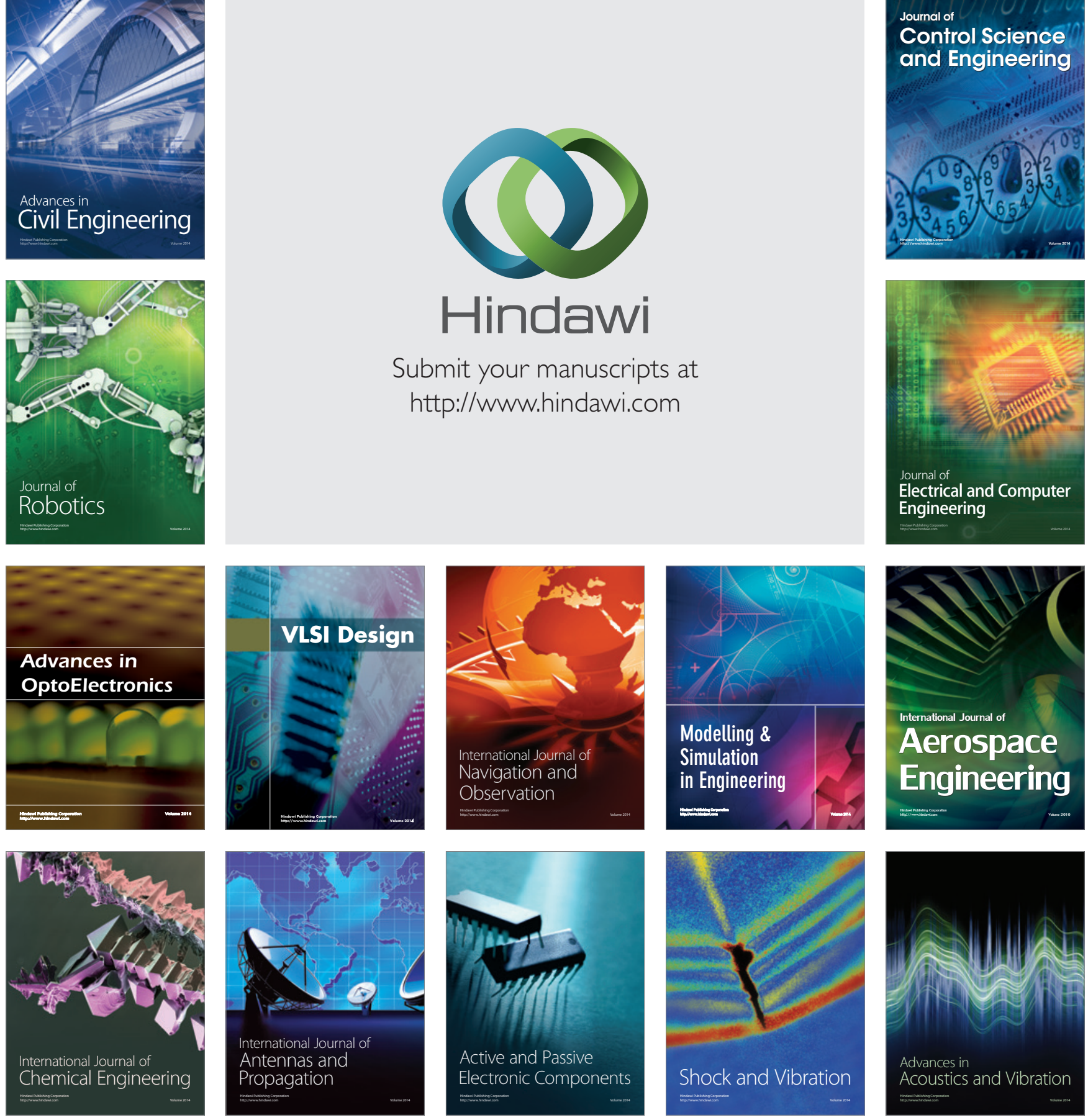